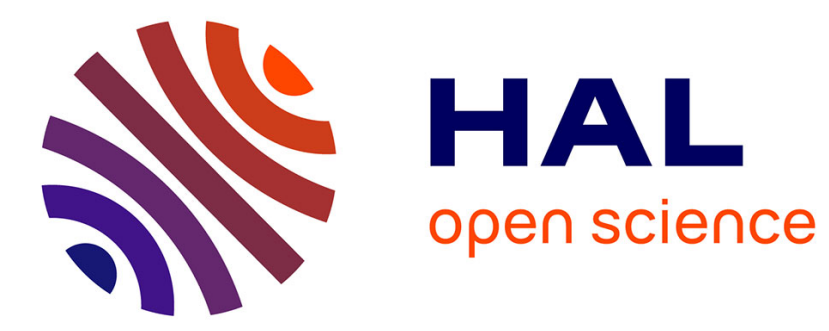

\title{
Influence of early re-spacing on Sitka spruce branch structure
}

\author{
Auty, Aaron Weiskittel, Achim, John Moore, Barry Gardiner
}

\section{To cite this version:}

Auty, Aaron Weiskittel, Achim, John Moore, Barry Gardiner. Influence of early re-spacing on Sitka spruce branch structure. Annals of Forest Science, 2012, 69 (1), pp.93-104. 10.1007/s13595-011-01418. hal-00930713

\section{HAL Id: hal-00930713 https://hal.science/hal-00930713}

Submitted on 1 Jan 2012

HAL is a multi-disciplinary open access archive for the deposit and dissemination of scientific research documents, whether they are published or not. The documents may come from teaching and research institutions in France or abroad, or from public or private research centers.
L'archive ouverte pluridisciplinaire HAL, est destinée au dépôt et à la diffusion de documents scientifiques de niveau recherche, publiés ou non, émanant des établissements d'enseignement et de recherche français ou étrangers, des laboratoires publics ou privés. 


\title{
Influence of early re-spacing on Sitka spruce branch structure
}

\author{
David Auty • Aaron R. Weiskittel - Alexis Achim • \\ John R. Moore • Barry A. Gardiner
}

Received: 13 July 2011 / Accepted: 18 September 2011 /Published online: 13 October 2011

(C) INRA and Springer-Verlag, France 2011

\begin{abstract}
- Context The frequency, size, and insertion angle of primary branches are important determinants of wood quality and can be significantly influenced by silvicultural activities.

- Aims This study quantified the long-term influence of early re-spacing on the branching characteristics of mature Sitka spruce [Picea sitchensis (Bong.) Carr.] trees growing in Northern Ireland, UK. The primary aim was to investigate whether any residual effect of stand density on branch attributes remained once the effect of changes in tree size variables had been considered, while a secondary
\end{abstract}

Handling Editor: Jean-Michel Leban

D. Auty $(\bowtie) \cdot$ A. Achim $\cdot$ B. A. Gardiner

Forest Research,

Roslin, Midlothian EH25 9SY, UK

e-mail: auty.david.1@ulaval.ca

\section{A. R. Weiskittel}

School of Forest Resources, University of Maine,

5755 Nutting Hall,

Orono, ME 04469, UK

J. R. Moore

Forest Products Research Institute, Edinburgh Napier University, Edinburgh EH10 5DT, UK

Present Address:

D. Auty $\cdot$ A. Achim

Département des Sciences du bois et de la Forêt, Université Laval,

Québec G1V 0A6, Canada

Present Address:

J. R. Moore

Scion (New Zealand Forest Research Institute Limited),

Private Bag 3020,

Rotorua 3046, New Zealand objective was to test the performance of existing Sitka spruce branch models using the current dataset.

- Methods Re-spacing treatments had corresponding stand densities of 2,858, 1,452, 725, 477, and 320 stems ha $^{-1}$. Twenty-four trees were sampled when the stand was 57 years old and branch frequency, size, and insertion angle were recorded for model development.

- Results Maximum branch diameter, insertion angle, and branch frequency were significantly influenced by re-spacing, while no effect was found for relative branch diameter distribution. Residual re-spacing effects were most noticeable on branch size, with only small differences between treatments for branch frequency and insertion angle. Existing models performed well despite the wider range of stand densities examined in the present study.

- Conclusion The results indicate that early re-spacing from $1.9 \mathrm{~m}^{2}$ to wider than $2.6 \mathrm{~m}^{2}$ will result in branch attributes that are detrimental to Sitka spruce sawn timber quality.

Keywords Picea sitchensis · Wood quality · Early re-spacing $\cdot$ Maximum branch size $\cdot$ Number of branches . Branch angle $\cdot$ Relative branch size

\section{Introduction}

Sitka spruce [Picea sitchensis (Bong.) Carr.] is the most commonly planted conifer species in the UK (Forestry Commission 2010) and Ireland (Joyce and OCarroll 2002) and is the main commercial species processed by the sawmilling and panel board industries in both these countries. Due to a significant increase in planting during the period spanning the 1950 s to the 1970 s, timber production is expected to gradually increase over the next 15-20 years in line with the current UK forecast (Halsall 
et al. 2006). Since Sitka spruce will account for over $80 \%$ of this increase, it will be necessary to increase the proportion of locally produced timber used in the larger and potentially higher-value construction market, as existing markets for nonstructural uses such as pallets, fencing, and packaging have become saturated. For this to occur, a greater proportion of Sitka spruce timber will have to meet the quality requirements demanded by end-users, which include strength class, as defined in Europe by EN338 (CEN 2003), dimensional stability, and visual appearance.

The quality of sawn timber is determined by the properties of the logs from which it is produced. For structural end uses, important wood properties include wood density, microfibril angle, and the size and frequency of knots, as these affect wood stiffness (MOE) and strength (MOR; Forest Products Laboratory 2010) and hence, the structural grade outturn under both visual and machine strength grading systems (Maun 1992; Zhang et al. 2002). In addition, problems can also occur when using excessively knotty timber in timber frame construction due to nail fouling. The characteristics of knots are, in turn, determined by branch attributes such as frequency, size, insertion angle, and status. Since these attributes are strongly influenced by growth characteristics and competition, there is potential for these to be modified by forest managers in order to improve the yield and performance of structural timber (Brazier 1977; Macdonald and Hubert 2002).

However, there are also concerns about the effects on timber quality of changes in UK silvicultural practices that were introduced in the 1960s and continued through to the 1980s, such as a move to wider initial spacings (Wardle 1967), partly to reduce establishment costs but also to improve the wind stability of stands, and increased planting of upland areas (Worrell 1987). These silvicultural trends may have had a detrimental effect on future Sitka spruce timber quality because increased tree growth is associated with larger knots, reduced wood density, and poorer stem form (Brazier 1970, 1977). For example, a recent study investigating the effects of an early re-spacing treatment on the physical and mechanical properties of Sitka spruce structural timber found that wide re-spacing resulted in a significant reduction in both MOE and MOR (Moore et al. 2009).

The wide range of silvicultural treatments applied by forest managers due to the competing objectives of multiuse forestry can influence timber quality both positively and negatively (Macdonald et al. 2010). To account for this variability, a modelling approach has evolved that links wood quality with tree growth in order to quantify predictions of end-use properties under different silvicultural scenarios (Houllier et al. 1995). Specifically, this approach enables wood quality attributes such as density (e.g. Guilley et al. 2004; Schneider et al. 2008; Gardiner et al. 2011), stem taper, (e.g. Tasissa and Burkhart 1998; Garber and Maguire 2003; Fonweban et al. 2011), and branch attributes (e.g. Maguire et al. 1991; Colin and Houllier 1992; Weiskittel et al. 2010) to be modelled as functions of tree diameter and height growth as influenced by silvicultural practices.

Using such a modelling approach, Achim et al. (2006) studied the changes in predicted branch characteristics of Sitka spruce following thinning through the effect on tree size variables (i.e. diameter and height). The authors found that while thinning had no influence on branch angle, it significantly increased branch frequency and size. However, this analysis was limited to the range of initial stand densities commonly used in the UK (e.g. approximately 1,750 3,500 stems $\mathrm{ha}^{-1}$; Achim et al. 2006), therefore it is uncertain whether the models will give accurate predictions for trees grown outside the range of conditions for which they were calibrated, even though such extrapolations are commonly made (Macdonald et al. 2010). In addition, Achim et al. (2006) did not explicitly consider the effect of stand density over and above the effect on tree growth (i.e. the marginal or additional effect of thinning treatment after the influence of tree size variables had been accounted for).

Therefore, the overall goal of this study was to quantify the influence of a wide range of re-spacing intensities on Sitka spruce branch attributes, in order to test the assumption that they can be explicitly modelled by linking them to tree growth. More specifically, we used a longestablished early re-spacing trial with a wide range of stand densities in order to test the hypothesis that there is no influence of re-spacing intensity on branch angle, frequency, and maximum as well as relative branch size in Sitka spruce over and above the effect that can be modelled using changes in tree size variables such as diameter at breast height or relative crown dimensions. A secondary objective was to establish whether existing models (i.e. Achim et al. 2006) can be successfully extrapolated beyond the range of stand densities for which they were originally developed.

\section{Methods}

\subsection{Experimental data}

Twenty-four trees were sampled from a re-spacing experiment at Baronscourt, in Co. Tyrone, Northern Ireland (latitude $54^{\circ} 41^{\prime} \mathrm{N}$, longitude $7^{\circ} 26^{\prime} \mathrm{W}, 140 \mathrm{~m}$ elevation). The 4-ha experimental site, with a yield class of $20 \mathrm{~m}^{3} \mathrm{ha}^{-1}$ year ${ }^{-1}$, was planted in 1949 at an initial spacing of $1.83 \times 1.83 \mathrm{~m}$, and re-spaced in 1960 . Five re-spacing treatments, which included the initial spacing, were applied to 25 plots of approximately 0.15 ha in size arranged in a 
$5 \times 5$ Latin square design. In addition to the initial spacing, re-spacing treatments were nominally $1.83 \times 3.66,3.66 \times$ $3.66,3.66 \times 5.49$, and $5.49 \times 5.49 \mathrm{~m}$, and the corresponding measured stand densities were $2,858,1,452,725,477$, and 320 stems $^{-1}{ }^{-1}$, respectively.

For brevity, we refer to the treatments by the equivalent square spacing used by Kilpatrick et al. (1981), i.e. approximately $1.9,2.6,3.7,4.6$, and $5.6 \mathrm{~m}^{2}$. The four wider re-spacing levels were achieved by systematically removing alternate rows and/or trees within a row. The experiment is described in more detail in Jack (1971) and growth and yield data for the first 31 years are presented in Kilpatrick et al. (1981). Due to significant mortality, the stand densities in the 1.9 and $2.6 \mathrm{~m}^{2}$ treatments at the time of sampling were significantly lower than in 1960 (Table 1). Due to past wind damage, one of the five plots in the $4.6 \mathrm{~m}^{2}$ spacing treatment was omitted as the growing space available to the trees was no longer representative of this treatment.

In 2006, when the stand was 57 years old, the diameter at breast height $(\mathrm{DBH})$ of every live tree in all plots was recorded. One dominant or co-dominant tree from each plot was randomly selected from the upper 50th percentile of the DBH distribution for destructive sampling. The DBH of these trees ranged from 33 to $76 \mathrm{~cm}$, and total height (HT, measured once the tree had been felled) ranged from 29.2 to $38.6 \mathrm{~m}$ (Table 1). Detailed branch attributes were measured using the approach described in Colin and Houllier (1991) and Achim et al. (2006).

In Sitka spruce, branches tend to form either in a distinct cluster in the upper portion of each annual shoot-more correctly termed 'pseudo-whorls' in the botanical literature (e.g. Heuret et al. 2006) - or along the length of each annual shoot. Here, we refer to these as nodal and internodal branches, respectively (Barthélémy and Caraglio 2007). On each annual shoot (i.e. the continuous elongation flush of the stem during a single growing season), the distance (DIST, metre) from the shoot base to the stem apex was measured and the annual shoot length (i.e. the internodal length, NLEN) was by calculated by subtracting DIST values for two successive annual shoots. On every fourth annual shoot, the position (i.e. nodal or internodal), status (i.e. alive or dead), vertical insertion angle (i.e. the angle of insertion relative to the upright stem, VBA), and horizontal and vertical diameters (near branch base, avoiding basal swelling) of each branch greater than $5 \mathrm{~mm}$ in diameter were recorded. Branch diameter (BD) was calculated as the arithmetic mean of the horizontal and vertical diameters. The relative branch diameter $\left(\mathrm{BD}_{\mathrm{REL}}\right)$ of each branch was determined as the diameter relative to the maximum branch diameter in each annual shoot $(\mathrm{BD} /$ $\left.\mathrm{BD}_{\mathrm{MAX}}\right)$. Crown length (CL) was defined as the distance (m) between the stem apex and the insertion point of the lowest living branch (i.e. the lowest branch containing live foliar tissue), and crown ratio (CR) was calculated as CL/ HT. Overall, a total of 2,528 branches were assessed on 295 annual shoots $(12.3 \pm 0.7$ annual shoots per tree).

\subsection{Data analysis}

Because the data had a hierarchical structure with branches clustered within annual shoots, that were themselves located within trees, a mixed-modelling approach similar to that employed by Hein et al. (2008a) was adopted to ensure that appropriate estimates of parameter standard errors were obtained and tests of parameter significance were valid (Pinheiro and Bates 2009). A linear mixedeffects modelling approach was used to analyse data on maximum branch diameter, relative branch diameter, and branch insertion angle. Because the number of branches per annual shoot represents count data and the mean counts per branch type were generally low (i.e. $<5$ ), a generalised
Table 1 Stand-level characteristics in 2006 for each re-spacing treatment and characteristics of the 24 sample trees on which branch attributes were measured

Where appropriate, standard errors of the mean are given in parentheses. Standard errors for stand-level characteristics are based on data from plots within a re-spacing treatment

$D B H$ diameter at breast height (cm), HT total tree height (m), $L L P W$ height $(\mathrm{m})$ of the lowest live pseudo-whorl of branches, $L L B$ lowest live branch height $(\mathrm{m})$

\begin{tabular}{|c|c|c|c|c|c|}
\hline \multirow[t]{2}{*}{ Attribute } & \multicolumn{5}{|c|}{ Re-spacing treatment $\left(\mathrm{m}^{2}\right)$} \\
\hline & 1.9 & 2.6 & 3.7 & 4.6 & 5.7 \\
\hline \multicolumn{6}{|l|}{ Stand } \\
\hline Stand density (stems ha ${ }^{-1}$ ) & $1,134(71)$ & $922(150)$ & $581(45)$ & $435(12)$ & $310(19)$ \\
\hline Mortality $(\%)$ & 60 & 37 & 20 & 9 & 3 \\
\hline $\mathrm{DBH}(\mathrm{cm})$ & 29.1 & 33.5 & 41.3 & 46.5 & 51.2 \\
\hline Height (m) & 32.8 & 34.5 & 34.9 & 36.2 & 35.8 \\
\hline \multicolumn{6}{|l|}{ Sample tree } \\
\hline $\mathrm{N}$ & 5 & 5 & 4 & 5 & 5 \\
\hline DBH (cm) & $38.9(5.7)$ & $36.9(5.1)$ & $40.3(6.9)$ & $55.6(5.7)$ & $65.9(9.1)$ \\
\hline Height (m) & $32.5(2.6)$ & $34.7(1.2)$ & $34.6(2.1)$ & $32.5(2.6)$ & $37.0(1.5)$ \\
\hline LLPW (m) & $23.1(1.8)$ & $24.3(1.6)$ & $24.5(1.6)$ & $23.1(1.8)$ & $21.1(1.5)$ \\
\hline LLB (m) & $22.3(1.7)$ & $23.6(1.8)$ & $23.4(2.0)$ & $22.3(1.8)$ & $20.3(1.1)$ \\
\hline
\end{tabular}


linear mixed-effects modelling approach, which assumes that counts follow a Poisson distribution (McCullagh and Nelder 1989), was used to model the number of branches. In the models for branch number and maximum branch diameter, random effects were included for tree, while random effects for tree and annual shoot were included in the models for relative branch diameter and branch insertion angle.

For each branch characteristic of interest, the final choice of explanatory variables to be included in the fixed part of the models were determined by comparing the results from various initial model fits using Akaike's information criterion (Akaike 1974) with a difference of 10 units being considered significant (Burnham and Anderson 2002, p. 71). In addition, data on the branch and annual shoot characteristics were treated as repeated measures along the stem or along a gradient within the annual shoot. Preliminary analysis of the data indicated there was a significant longitudinal correlation, and a continuous autoregressive model was included to account for this (Pinheiro and Bates 2009). The significance of both the random effects terms and the correlation function in each model were determined using likelihood ratio tests. Only those parameters that were significant $(p<0.05)$ were retained in the final models, except where interaction terms were included in the models, in which case all fixed-effects parameters are reported. Multiple comparisons between re-spacing treatments were carried out using Tukey's adjustment. All data analyses were performed using the functions contained in the lme4, nlme, and multcomp libraries of the $\mathrm{R}$ statistical software programming environment ( $R$ Development Core Team 2011), except the maximum branch diameter model which was fitted in Statistical Analysis System (SAS) using the PROC MIXED procedure (Littel et al. 2002). In the latter case, SAS was used rather than $\mathrm{R}$ as the latter currently lacks the facility to carry out multiple comparisons when significant model interaction terms that include the factor of interest are encountered.

Initially, all models were developed without tree or crown size variables in the fixed-effects predictors, as these are affected by stand density. First, base models were developed for each branch characteristic of interest, and included re-spacing as a categorical factor in the fixed effects. The $1.9 \mathrm{~m}^{2}$ re-spacing treatment was used as the reference treatment in all models. Next, tree or crown size variables were added to the fixed effects of each model in order to determine the marginal effect of re-spacing intensity on branch characteristics once any effects attributable to changes in tree size and crown dimensions had been accounted for. Several tree- and crown-level variables were screened, including $\mathrm{DBH}, \mathrm{CL}, \mathrm{CR}$, and HT/DBH ratio. Although there were minor differences in the number of trees in each plot, preliminary analysis (results not shown) indicated that the inclusion of re-spacing treatment as a categorical factor was a more effective approach than using a continuous measure of stand density. Because data from both live and dead branches along the stem were used in developing the final equations, any effect of branch status on branch attributes was evaluated by adding an indicator variable ( 1 if live branch, 0 if dead branch) to each model.

For comparative purposes, the model forms and parameter estimates developed by Achim et al. (2006) were also applied to this dataset in order to predict branch number and insertion angle. Since the model for branch diameter developed by Achim et al. (2006) predicts the mean branch diameter in an annual shoot, it could not be compared to the model of maximum branch diameter developed in this study.

\subsubsection{Branch number}

Separate models were developed to predict the number of nodal $\left(\mathrm{NB}_{N}\right)$ and internodal branches $\left(\mathrm{NB}_{I}\right)$ in an annual shoot, as well as the total number of branches $\left(\mathrm{NB}_{T}\right)$. Following the approach taken by Hein et al. (2008a), branch number in each annual shoot for each branch type was related to both the annual shoot length and the annual shoot height in the stem:

$$
\begin{aligned}
\mathrm{NB}_{N}= & a_{0}+a_{1} \mathrm{NLEN}+a_{2} \mathrm{NHT}+a_{3} \mathrm{DBH}+a_{4} \mathrm{SP}_{2.6}+a_{5} \mathrm{SP}_{3.7} \\
& +a_{6} \mathrm{SP}_{4.6}+a_{7} \mathrm{SP}_{5.7}+\delta_{\text {tree }}
\end{aligned}
$$

$$
\begin{aligned}
\mathrm{NB}_{I}= & b_{0}+b_{1} \mathrm{NLEN}+b_{2} \mathrm{NHT}+b_{3} \mathrm{DBH}+b_{4} \mathrm{SP}_{2.6} \\
& +b_{5} \mathrm{SP}_{3.7}+b_{6} \mathrm{SP}_{4.6}+b_{7} \mathrm{SP}_{5.7}+\delta_{\text {tree }}
\end{aligned}
$$

$$
\begin{aligned}
\mathrm{NB}_{T}= & c_{0}+c_{1} \mathrm{NLEN}+c_{2} \mathrm{NHT}+c_{3} \mathrm{DBH}+c_{4} \mathrm{SP}_{2.6} \\
& +c_{5} \mathrm{SP}_{3.7}+c_{6} \mathrm{SP}_{4.6}+c_{7} \mathrm{SP}_{5.7}+\delta_{\text {tree }}
\end{aligned}
$$

where NLEN is the annual shoot length (m), NHT is the height in the stem (m) of each annual shoot (i.e. HT - DIST), DBH is tree diameter at breast height $(\mathrm{cm}), a_{1} \ldots a_{7}, b_{1} \ldots b_{7}$ and $c_{0} \ldots c_{7}$ are parameters to be estimated from the data and $\delta_{\text {tree }}$ is a random effect for each tree. $\mathrm{SP}_{2.6}, \mathrm{SP}_{3.7}, \mathrm{SP}_{4.6}$, and $\mathrm{SP}_{5.6}$ are indicator variables for the $2.6,3.7,4.6$, and $5.6 \mathrm{~m}^{2}$ re-spacing treatments, respectively.

The number of nodal and internodal branches in an annual shoot was also predicted for the model-fitting dataset using the following equation developed by Achim et al. (2006):

$\mathrm{NB}_{N, I}=i_{N, I} \mathrm{NLEN}^{a_{N, I}} e^{\left(-b_{N, I} \mathrm{DIST}\right)}$ 
where NLEN and DIST are as previously defined and $i_{N, I}$, $a_{N, I}$ and $b_{N, I}$ were modelled as functions of the tree-level variables HT and DBH for both nodal and internodal branches, i.e.:

$i_{N}=5.71-0.0084 \mathrm{HT} \quad i_{I}=12.49-0.18 \mathrm{H}$

$a_{N}=0.19 \quad a_{I}=0.71-0.56 \mathrm{DBH}+0.0034 \frac{\mathrm{HT}}{\mathrm{DBH}^{*}}$

$b_{N}=-0.089+0.072 \mathrm{DBH}+0.0055 \frac{\mathrm{HT}}{\mathrm{DBH}^{*}} \quad b_{I}=0.23$

where $\mathrm{DBH}^{*}$ is in metres to ensure correspondence of units.

\subsubsection{Maximum branch diameter}

The diameter of the thickest branch in each annual shoot was modelled using the following linear equation:

$$
\begin{aligned}
\mathrm{BD}_{\mathrm{MAX}}= & d_{0}+d_{1} \mathrm{DIST}+d_{2} \ln (\mathrm{DIST})+d_{3} \mathrm{CR} \\
& +d_{4} \mathrm{SP}_{2.6}+d_{5} \mathrm{SP}_{3.7}+d_{6} \mathrm{SP}_{4.6}+d_{7} \mathrm{SP}_{5.6} \\
& +d_{8}\left(\mathrm{SP}_{2.6} \times \mathrm{DIST}\right)+d_{9}\left(\mathrm{SP}_{3.7} \times \mathrm{DIST}\right) \\
& +d_{10}\left(\mathrm{SP}_{4.6} \times \mathrm{DIST}\right) \\
& +d_{11}\left(\mathrm{SP}_{5.6} \times \mathrm{DIST}\right)+\delta_{\text {tree }}
\end{aligned}
$$

where $\mathrm{BD}_{\mathrm{MAX}}$ is the maximum branch diameter $(\mathrm{mm})$, DIST is the distance of each annual shoot from the stem apex (m), $\ln$ (DIST) denotes the natural logarithm of DIST, $\mathrm{SP} \times \mathrm{DIST}$ is an interaction term, $d_{0} \ldots d_{11}$ are parameters to be estimated from the data and $\delta_{\text {tree }}$ represents the tree-level random effect.

\subsubsection{Relative branch diameter}

The relative diameter of all branches in an annual shoot is an important attribute because it describes the size variation of branches on a stem and allows the diameter of any branch in an annual shoot to be estimated if the number of branches and the maximum branch diameter are known. The relative diameter of all branches in an annual shoot, except the largest, was modelled using a modified version of the linear equation presented in Hein et al. (2008a):

$$
\begin{aligned}
\mathrm{BD}_{\mathrm{REL}}= & e_{0}+e_{1} \mathrm{RANK}+e_{2} \ln (\mathrm{RANK})+e_{3} \mathrm{NB}_{T} \\
& +e_{4} \mathrm{NHT}+e_{5} N+e_{6} \mathrm{SP}_{2.6}+e_{7} \mathrm{SP}_{3.7} \\
& +e_{8} \mathrm{SP}_{4.6}+e_{9} \mathrm{SP}_{5.6}+\delta_{\text {tree }}+\delta_{\text {shoot }}
\end{aligned}
$$

where $\mathrm{BD}_{\mathrm{REL}}$ is branch relative diameter within an annual shoot $\left(\mathrm{BD} / \mathrm{BD}_{\mathrm{MAX}}\right)$, RANK is the branch rank within an annual shoot (e.g. 1 for $\mathrm{BD}_{\mathrm{MAX}}, 2$ for the next largest branch, etc.), $\ln$ (RANK) the natural logarithm of RANK, $\mathrm{NB}_{T}$ is the total number of branches within the annual shoot, $N$ is an indicator for branch type ( 1 if nodal branch, 0 if internodal branch), and $e_{0} \ldots e_{9}$ are parameters to be estimated from the data. $\delta_{\text {shoot }}$ is the random effect for each annual shoot.

\subsubsection{Branch insertion angle}

The angle of insertion of a branch relative to the vertical stem was modelled using the following linear equation:

$$
\begin{aligned}
\mathrm{VBA}= & g_{0}+g_{1} \mathrm{BD}+g_{2} \mathrm{DIST}+g_{3} \ln (\mathrm{DIST}) \\
& +g_{4}(\mathrm{BD} \times \mathrm{DIST})+g_{5} N+g_{6} L+g_{7} \mathrm{SP}_{2.6} \\
& +g_{8} \mathrm{SP}_{3.7}+g_{9} \mathrm{SP}_{4.6}+g_{10} \mathrm{SP}_{5.6} \\
& +\delta_{\text {tree }}+\delta_{\text {shoot }}
\end{aligned}
$$

where VBA is the vertical branch angle $\left(^{\circ}\right), \mathrm{BD} \times \mathrm{DIST}$ is an interaction term, $L$ is an indicator variable for branch status ( 1 if live branch, 0 if dead branch), $g_{0} \ldots g_{10}$ are parameters to be estimated from the data, and all other variables are as defined previously.

VBA of nodal $\left(\mathrm{VBA}_{N}\right)$ and internodal $\left(\mathrm{VBA}_{I}\right)$ branches was also predicted for the model-fitting dataset using the following equations developed by Achim et al. (2006):

$\mathrm{VBA}_{N}=72.87 e^{-\frac{0.0028}{1-Z}}$

$\mathrm{VBA}_{I}=85.6 e^{-\frac{0.0013}{0.99-Z}}$

where $Z$ is the relative distance of each annual shoot from the stem apex (DIST/HT).

\subsubsection{Evaluation of model performance}

The performance of the fixed part of each of the models was examined by calculating the mean error $(E)$, mean absolute error $(|E|)$, and mean percentage error $(E \%)$ using the model-fitting dataset. $E$ and $|E|$ were calculated using the equations presented in Hein et al. (2008a), while $E \%$ was calculated using the following equation:

$E \%=\frac{100}{n} \sum \frac{\left|y_{i}-\widehat{y}_{i}\right|}{\widehat{y}_{i}}$

where $y_{i}$ is the observed value, $\widehat{y}_{i}$ the predicted value, and $n$ is the number of observations. Error statistics were also calculated for the models developed by Achim et al. (2006) using the current dataset. A fit index $\left(R^{2}\right)$ was also calculated for each model using the equation given in Parresol (1999). Two sets of fit indices were calculated. In the first set, the predicted values were estimated from the 
fixed-effects terms of each model, and in the second, from both the fixed and random effects. In addition, plots of model residuals versus fitted and explanatory variables were visually inspected for any obvious trends.

\section{Results}

Branch diameter ranged from 5 to $73 \mathrm{~mm}$ with a mean of $19 \mathrm{~mm}$, while branch insertion angle ranged from $20^{\circ}$ to $170^{\circ}$ with a mean of $78^{\circ}$ (Table 2). The mean numbers of nodal and internodal branches were 3.7 and 4.9 , respectively. The relative branch diameter was, on average, $0.52 \pm$ 0.28 . Overall, there was a significant amount of within- and between-tree variation in the branch properties examined (Fig. 1).

\subsection{Model evaluation}

\subsubsection{Branch number}

The number of branches in an annual shoot increased with increasing annual shoot length as well as with increasing DBH (Table 3). The number of internodal branches and the total number of branches increased with increasing annual shoot height in the stem, while the number of nodal branches decreased. After accounting for annual shoot length, height in the stem, and DBH, re-spacing still had a significant effect on the number of both nodal and internodal branches $(p<0.05$; Fig. 2). For nodal branches, the most significant differences were between the 1.9 and $3.7 \mathrm{~m}^{2}$ treatments $(p<0.001)$ and the 1.9 and $2.6 \mathrm{~m}^{2}$ re-spacing treatments $(p<0.05)$, while the $4.6 \mathrm{~m}^{2}$ re-spacing treatment was significantly different from the $1.9 \mathrm{~m}^{2}$ re-spacing treatment at the $10 \%$ level $(p=0.06)$. For internodal branches, the only significant difference observed was between the 1.9 and $5.7 \mathrm{~m}^{2}$ re-spacing treatments $(p=0.007)$. The fixed effects of the models given by Eqs. $1 \mathrm{a}$ and $1 \mathrm{~b}$ explained $30 \%$ and $41 \%$ of the original variation in the number of nodal and internodal branches, respectively, and there were no obvious trends in the model residuals when plotted against the fitted values or explanatory variables (not shown).

For the combined number of nodal and internodal branches, Eq. 1c explained $42 \%$ of the variation in total number of branches per annual shoot, while the only significant difference observed was between the 1.9 and $5.7 \mathrm{~m}^{2}$ re-spacing treatments $(p=<0.001)$. The mean error and mean absolute error calculated from the fixed effects of Eq. 1c were -0.001 and 2.2 branches per annual shoot, respectively (Table 4). In comparison, the corresponding model developed by Achim et al. (2006) had a mean error and mean absolute error of 1.46 and 3.01 branches per annual shoot, respectively, when applied to this dataset (Table 4). There was no significant effect of branch status in the models for branch frequency.

\subsubsection{Maximum branch diameter}

Maximum branch diameter was positively related to crown ratio and had a curvilinear relationship with distance from

Table 2 Summary of the branch properties by re-spacing intensity

\begin{tabular}{|c|c|c|c|c|c|}
\hline \multirow[t]{2}{*}{ Attribute } & \multicolumn{5}{|c|}{ Re-spacing treatment $\left(\mathrm{m}^{2}\right)$} \\
\hline & 1.9 & 2.6 & 3.7 & 4.6 & 5.7 \\
\hline \# Observations & 530 & 499 & 457 & 515 & 527 \\
\hline$\%$ Branches alive & 41.8 & 45.4 & 36.3 & 44.6 & 50.1 \\
\hline \# Annual shoots sampled per tree & 12.2 & 12.6 & 12.2 & 12.8 & 11.8 \\
\hline \multirow[t]{2}{*}{$\mathrm{NB}_{N}$} & $3.1(0.9)$ & $3.6(1.4)$ & $3.9(1.2)$ & $4.6(1.5)$ & $4.1(1.1)$ \\
\hline & {$[1,5]$} & {$[1,10]$} & {$[1,8]$} & {$[2,9]$} & {$[2,7]$} \\
\hline \multirow[t]{2}{*}{$\mathrm{NB}_{I}$} & $6.5(4.0)$ & $5.1(3.4)$ & $4.4(3.3)$ & $6.2(5.3)$ & $5.6(3.7)$ \\
\hline & {$[0,16]$} & {$[0,15]$} & {$[0,12]$} & {$[0,20]$} & {$[0,19]$} \\
\hline \multirow[t]{2}{*}{$\mathrm{BD}_{\mathrm{MAX}}$} & $29(9.9)$ & $32(10.1)$ & $29(9.7)$ & $42(13.1)$ & $45(16.0)$ \\
\hline & {$[7,48]$} & {$[5,49]$} & {$[1,46]$} & {$[10,62]$} & {$[1,73]$} \\
\hline \multirow[t]{2}{*}{$\mathrm{BD}_{\mathrm{REL}}$} & $0.52(0.30)$ & $0.58(0.31)$ & $0.59(0.31)$ & $0.55(0.31)$ & $0.59(0.31)$ \\
\hline & {$[0.07,1.00]$} & {$[0.02,1.00]$} & {$[0.05,1.00]$} & {$[0.10,1.00]$} & {$[0.05,1.00]$} \\
\hline \multirow[t]{2}{*}{ VBA } & $82(18)$ & $75(15)$ & 75 (15) & 80 (17) & $79(15)$ \\
\hline & {$[30,170]$} & {$[25,150]$} & {$[25,140]$} & {$[20,140]$} & {$[20,140]$} \\
\hline
\end{tabular}

Mean values are presented followed by standard deviations in parentheses and the range of values in square brackets

$N B_{N}$ number of nodal branches per annual shoot, $N B_{I}$ number of internodal branches per annual shoot, $B D_{M A X}$ the maximum branch diameter per annual shoot $(\mathrm{mm}), B D_{R E L}$ relative branch size $\left(\mathrm{BD} / \mathrm{BD}_{\mathrm{MAX}}\right)$, and $V B A$ vertical branch insertion angle $\left(^{\circ}\right)$ 
Fig. 1 Beanplots (Kampstra 2008) showing the distributions of number of branches per annual shoot, branch size, branch angle, and relative branch size by re-spacing treatment. Dotted lines overall mean, solid lines group means
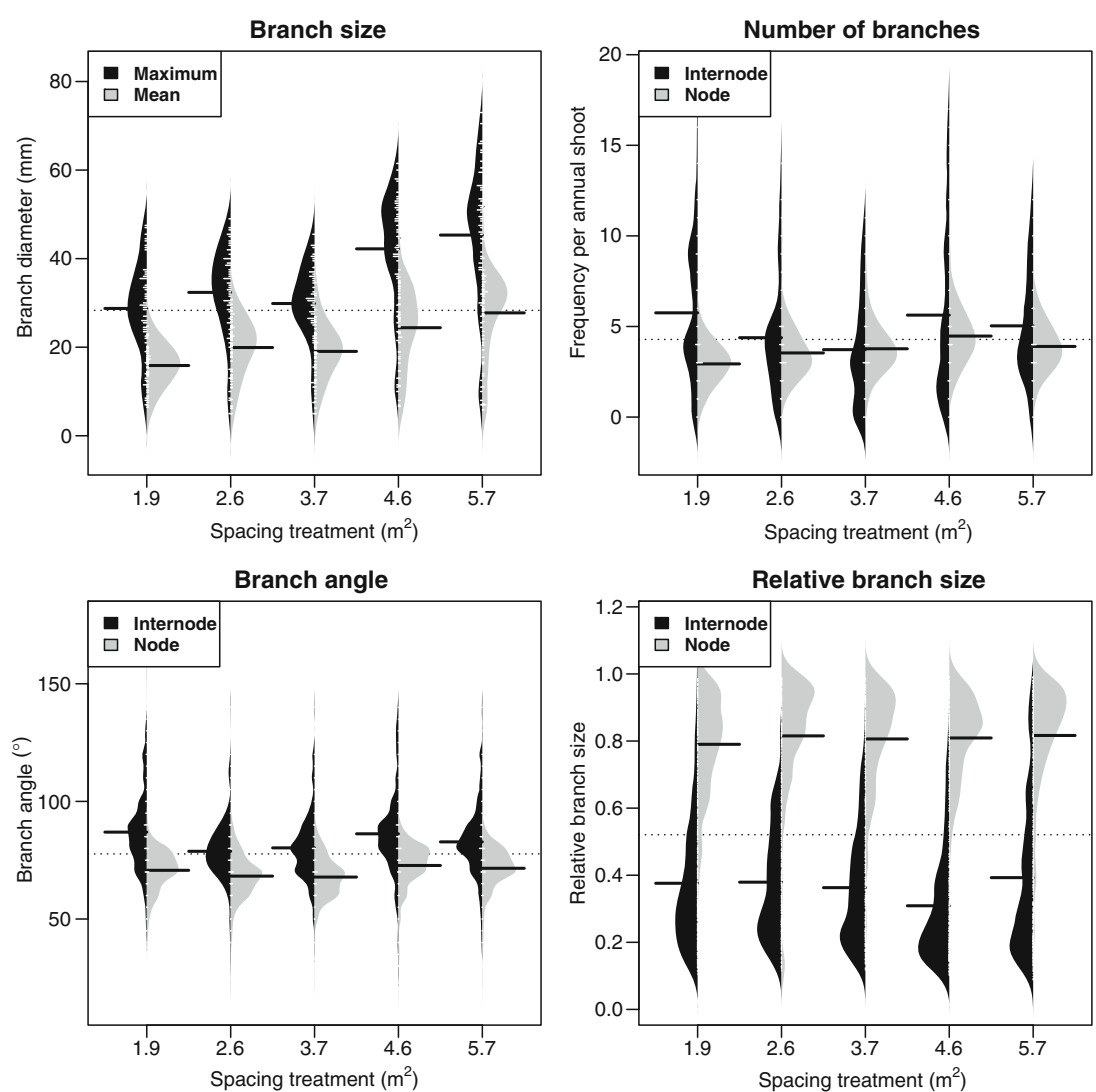

the stem apex (Table 3). After these effects were taken into account, re-spacing had a significant influence on maximum branch diameter. When compared to the $1.9 \mathrm{~m}^{2}$ respacing treatment, maximum branch diameter was significantly larger in the $4.6 \mathrm{~m}^{2}(p=<0.001)$ and $5.6 \mathrm{~m}^{2}(p=$ 0.015) treatments (Fig. 3). The fixed effects of the model were able to explain almost $75 \%$ of the variation in $\mathrm{BD}_{\mathrm{MAX}}$. Mean error and mean absolute error in $\mathrm{BD}_{\mathrm{MAX}}$ were 0.01 and $5.3 \mathrm{~mm}$, respectively, while the mean percentage error was $19.7 \%$. There were no trends in the model residuals when plotted against the fitted values or explanatory variables from the model (not shown), and there was no additional effect of branch status on maximum branch diameter.

\subsubsection{Relative branch diameter}

Relative branch diameter was positively related to the number of branches within an annual shoot and was higher in nodal branches, while it decreased with annual shoot height in the stem and had a curvilinear relationship with branch rank (Table 3). There was no effect of re-spacing on relative branch diameter within an annual shoot, and no effect of branch status on relative branch size. Overall, the fixed effects of the model explained $77 \%$ of the variation in $\mathrm{BD}_{\mathrm{REL}}$, and the mean error, mean absolute error, and mean percentage error were $-0.01,0.11$, and $25.4 \%$, respectively. There was no trend in the model residuals when plotted against the fitted values or explanatory variables (not shown).

\subsubsection{Branch insertion angle}

Vertical branch insertion angle had a curvilinear relationship with distance from the stem apex, increasing rapidly in the upper crown before levelling off and then decreasing towards the stem base. VBA also decreased with increasing branch diameter, the effect of which was greater with increasing distance from the stem apex. Insertion angle in nodal branches was slightly lower compared with internodal branches, while it was generally higher in live rather than in dead branches (Table 3; Fig. 4). There was a significant difference in branch insertion angle between re-spacing treatments after accounting for these effects $(p<0.001)$. In general, the smallest branch angles were in the 2.6 and $3.7 \mathrm{~m}^{2}$ treatments, although only the latter treatment was statistically different from the $1.9 \mathrm{~m}^{2}$ re-spacing treatment $(p=0.02)$. However, the $1.9 \mathrm{~m}^{2}$ treatment was not statistically different from either the 4.6 or $5.7 \mathrm{~m}^{2}$ treatments $(p=$ 0.822 and 0.992 , respectively). Where statistically significant differences were observed, the mean differences were generally less than $5^{\circ}$. There were no observed trends in the 
Table 3 Parameter estimates, standard errors and $p$-values for the equations used in this analysis

\begin{tabular}{|c|c|c|c|}
\hline Parameter & Estimate & Standard error & p-value \\
\hline \multicolumn{4}{|c|}{$\mathrm{NB}_{N}$ (Eq. 1a) } \\
\hline $\mathrm{a}_{0}$ & 0.5338 & 0.1486 & 0.0004 \\
\hline$a_{1}$ & 0.2895 & 0.0827 & 0.0005 \\
\hline $\mathrm{a}_{2}$ & -0.0095 & 0.0018 & 0.0001 \\
\hline$a_{3}$ & 0.0130 & 0.0032 & 0.0007 \\
\hline $\mathrm{a}_{4}$ & 0.1915 & 0.0614 & 0.0059 \\
\hline$a_{5}$ & 0.2778 & 0.0613 & 0.0003 \\
\hline $\mathrm{a}_{6}$ & 0.2060 & 0.0796 & 0.0186 \\
\hline \multicolumn{4}{|c|}{$\mathrm{NB}_{I}$ (Eq. 1b) } \\
\hline $\mathrm{b}_{0}$ & -1.0703 & 0.3432 & 0.0020 \\
\hline $\mathrm{b}_{1}$ & 1.6804 & 0.1864 & $<0.0001$ \\
\hline $\mathrm{b}_{2}$ & 0.0467 & 0.0048 & $<0.0001$ \\
\hline $\mathrm{b}_{3}$ & 0.0165 & 0.0070 & 0.0311 \\
\hline $\mathrm{b}_{6}$ & -0.3919 & 0.1660 & 0.0297 \\
\hline $\mathrm{b}_{7}$ & -0.7403 & 0.2268 & 0.0043 \\
\hline \multicolumn{4}{|c|}{$\mathrm{NB}_{T}$ (Eq. 1c) } \\
\hline $\mathrm{c}_{0}$ & 0.4828 & 0.1664 & 0.0040 \\
\hline $\mathrm{c}_{1}$ & 0.9338 & 0.0971 & $<0.0001$ \\
\hline $\mathrm{c}_{2}$ & 0.0190 & 0.0022 & $<0.0001$ \\
\hline $\mathrm{c}_{3}$ & 0.0160 & 0.0035 & 0.0002 \\
\hline $\mathrm{c}_{7}$ & -0.4644 & 0.1130 & 0.0007 \\
\hline \multicolumn{4}{|c|}{$\mathrm{BD}_{\mathrm{MAX}}$ (Eq. 3) } \\
\hline $\mathrm{d}_{0}$ & 5.8781 & 3.8380 & 0.1268 \\
\hline $\mathrm{d}_{1}$ & -1.7729 & 0.1299 & $<0.0001$ \\
\hline $\mathrm{d}_{2}$ & 16.3413 & 0.6967 & $<0.0001$ \\
\hline $\mathrm{d}_{3}$ & 37.3611 & 10.9709 & 0.0008 \\
\hline $\mathrm{d}_{4}$ & -1.4772 & 2.0003 & 0.4609 \\
\hline $\mathrm{d}_{5}$ & -2.1133 & 2.0200 & 0.2964 \\
\hline $\mathrm{d}_{6}$ & -5.3935 & 2.6064 & 0.0395 \\
\hline $\mathrm{d}_{7}$ & -2.5679 & 2.5371 & 0.3124 \\
\hline $\mathrm{d}_{8}$ & 0.3553 & 0.1524 & 0.0205 \\
\hline $\mathrm{d}_{9}$ & 0.2271 & 0.1559 & 0.1466 \\
\hline $\mathrm{d}_{10}$ & 0.8516 & 0.1581 & $<0.0001$ \\
\hline $\mathrm{d}_{11}$ & 0.8870 & 0.1514 & $<0.0001$ \\
\hline \multicolumn{4}{|c|}{$\mathrm{BD}_{\text {REL }}$ (Eq. 4) } \\
\hline $\mathrm{e}_{0}$ & 0.8624 & 0.0253 & $<0.0001$ \\
\hline $\mathrm{e}_{1}$ & -0.0148 & 0.0043 & 0.0006 \\
\hline $\mathrm{e}_{2}$ & -0.2808 & 0.0208 & $<0.0001$ \\
\hline$e_{3}$ & 0.0186 & 0.0017 & $<0.0001$ \\
\hline $\mathrm{e}_{4}$ & -0.0030 & 0.0006 & $<0.0001$ \\
\hline$e_{5}$ & 0.1862 & 0.0061 & $<0.0001$ \\
\hline \multicolumn{4}{|c|}{ VBA (Eq. 5) } \\
\hline $\mathrm{g}_{0}$ & 78.4865 & 2.2204 & $<0.0001$ \\
\hline $\mathrm{g}_{1}$ & -0.7097 & 0.0489 & $<0.0001$ \\
\hline $\mathrm{g}_{2}$ & -1.1167 & 0.1086 & $<0.0001$ \\
\hline$g_{3}$ & 10.6581 & 1.1013 & $<0.0001$ \\
\hline $\mathrm{g}_{4}$ & 0.0216 & 0.0020 & $<0.0001$ \\
\hline $\mathrm{g}_{5}$ & -5.3886 & 0.6774 & $<0.0001$ \\
\hline
\end{tabular}

Table 3 (continued)

\begin{tabular}{lrcr}
\hline Parameter & Estimate & Standard error & p-value \\
\hline $\mathrm{g}_{6}$ & 5.4260 & 1.0381 & $<0.0001$ \\
$\mathrm{~g}_{7}$ & -4.9653 & 1.9436 & 0.0194 \\
$\mathrm{~g}_{8}$ & -5.9530 & 1.9569 & 0.0067 \\
\hline
\end{tabular}

Nonsignificant $(p>0.05)$ parameters were omitted from the final models, except where re-spacing treatment was included as an interaction term, in which case all parameters are presented (i.e., Eq. 3)

model residuals when plotted against the fitted values or fixed-effects variables of the model (not shown).

The fixed-effects terms in the model developed in this study accounted for just less than $33 \%$ of the variation in branch insertion angle, and the mean error and mean absolute error were $-0.1^{\circ}$ and $8.8^{\circ}$, respectively (Table 4). By comparison, the model developed by Achim et al. (2006) had a mean error of $-2.5^{\circ}$ and a mean absolute of error of $10.1^{\circ}$ when applied to this dataset (Table 4).

\section{Discussion}

Sitka spruce is an important commercial species in Northern Europe, Canada and the USA, and knowledge of its long-term response to different silvicultural treatments is needed in order to design effective regimes. The results of the current study demonstrate that, in the models for branch frequency and maximum branch size, the inclusion of DBH and $\mathrm{CR}$, respectively, partially accounted for the effects of re-spacing, but significant differences remained, particularly in the most extreme treatments (i.e. 1.9 and $5.6 \mathrm{~m}^{2}$ ). Similarly, Moore et al. (2009) found that branch index

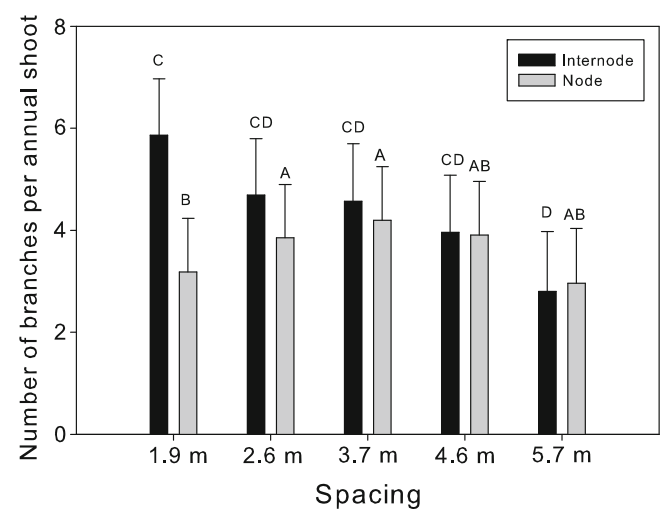

Fig. 2 Predicted numbers of nodal and internodal branches (with standard errors) per annual shoot using Eqs. 1a and $1 \mathrm{~b}$ by re-spacing treatment for the mean annual shoot length, annual shoot height, and diameter at breast height of the trees sampled in this study. Different letters indicate significant differences between groups based on Tukey's test at $\alpha=0.05$ 
Table 4 Comparison of mean error $(E)$, mean absolute error $(|E|)$, and mean percentage error $(E \%)$ for the equations for branch angle and total number of branches developed in this analysis (fixed effects only) and Achim et al. (2006) by re-spacing treatment

\begin{tabular}{|c|c|c|c|c|c|c|c|c|c|c|c|c|}
\hline \multirow[t]{3}{*}{ Re-spacing $\left(\mathrm{m}^{2}\right)$} & \multicolumn{6}{|c|}{ Branch angle $\left({ }^{\circ}\right)$} & \multicolumn{6}{|c|}{ Total number of branches (nodal+internodal) } \\
\hline & \multicolumn{3}{|l|}{ Eq. 5} & \multicolumn{3}{|c|}{ Achim et al. (2006) } & \multicolumn{3}{|l|}{ Eq. 1c } & \multicolumn{3}{|c|}{ Achim et al. (2006) } \\
\hline & $\mathrm{E}$ & $|\mathrm{E}|$ & $\mathrm{E} \%$ & $\mathrm{E}$ & $|\mathrm{E}|$ & $\mathrm{E} \%$ & $\mathrm{E}$ & $|\mathrm{E}|$ & $\mathrm{E} \%$ & $\mathrm{E}$ & $|\mathrm{E}|$ & $\mathrm{E} \%$ \\
\hline 1.9 & 0.60 & 0.63 & 11.70 & 0.10 & 10.74 & 13.03 & -0.001 & 2.12 & 25.43 & 1.99 & 3.23 & 47.99 \\
\hline 2.6 & -0.49 & 7.99 & 10.70 & -5.91 & 9.93 & 12.37 & -0.003 & 2.05 & 26.52 & 1.33 & 2.58 & 38.79 \\
\hline 3.7 & -1.05 & 8.30 & 11.37 & -5.26 & 10.03 & 12.55 & -0.001 & 2.13 & 29.02 & 0.79 & 2.56 & 37.63 \\
\hline 4.6 & -0.96 & 9.43 & 11.51 & 0.23 & 10.35 & 12.73 & -0.001 & 2.33 & 22.54 & 3.21 & 3.78 & 54.43 \\
\hline 5.7 & -0.64 & 8.69 & 10.99 & -2.21 & 9.37 & 11.55 & 0.004 & 2.41 & 27.72 & 2.21 & 3.05 & 45.41 \\
\hline Overall & -0.10 & 8.83 & 11.25 & -2.52 & 10.09 & 12.44 & -0.001 & 2.20 & 26.37 & 1.86 & 3.01 & 44.48 \\
\hline
\end{tabular}

(defined as the mean of the six largest branches per tree) was similar for the three narrowest re-spacing treatments in the same re-spacing trial, but was substantially greater in the two widest treatments. They also found that the total area of knots on sawn timber from this experimental site was similar in the 1.9 and $2.6 \mathrm{~m}^{2}$ re-spacing treatments, but was significantly higher in the $3.7,4.6$, and $5.6 \mathrm{~m}^{2}$ treatments.

The presence of a residual effect of spacing in addition to that expressed through tree size variables alone indicates that the allometric relationships between crown size and stem diameter may change in trees grown at wider spacings. This has also been observed in other studies (e.g. Garber and Maguire 2005; Hein et al. 2008b). In practice, this result reveals a potential limitation of a modelling approach that links branch characteristics with tree growth, as it shows that such relationships may not be totally independent of a prior knowledge of the silvicultural history of a given stand. This highlights the need to calibrate future wood quality models with data from a wide

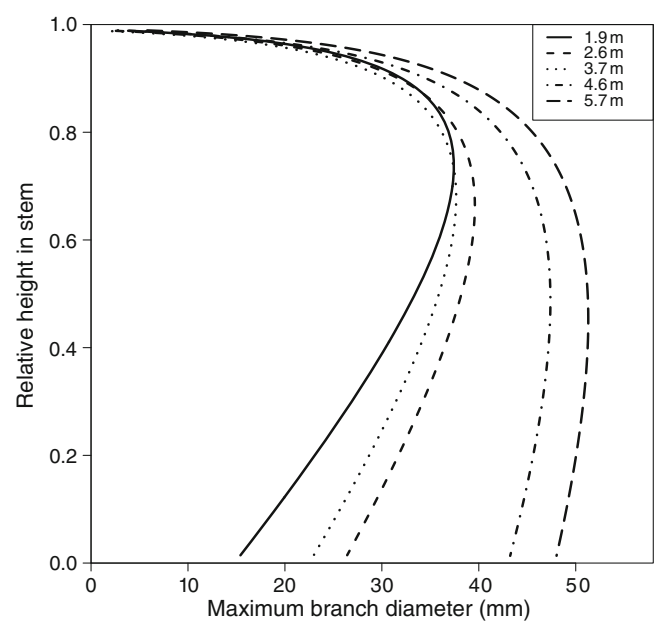

Fig. 3 Maximum branch diameter profiles predicted using Eq. 3 by re-spacing treatment for the mean crown ratio values in each treatment range of silvicultural treatments and stand conditions, and illustrates the potential problems of using static assessments to represent dynamic processes such as crown development.

The results of the present study were also generally consistent with those of Achim et al. (2006). In both studies, branch diameters showed a peak just above the crown base regardless of re-spacing treatment, and there was no drastic influence of stand density on branch insertion angle. Maximum branch diameters were generally $10-15 \%$ larger in the 4.6 and $5.6 \mathrm{~m}^{2}$ re-spacing treatments when compared to the other treatments. However, in the lower crown, the branches could be $>120 \%$ larger. This could clearly affect the visual appearance of sawn timber as well as its mechanical properties (Moore et al. 2009). Overall, the responsiveness of Sitka spruce branch diameter to stand density manipulation was similar to that observed in Douglas-fir. For example, using data from a Douglas-fir re-spacing trial, Weiskittel et al. (2007) found that there was only a $\sim 10 \%$ increase in maximum branch diameter in the heavy thinning treatment (approximately 250 residual stems $\left.\mathrm{ha}^{-1}\right)$ relative to the control $\left(\sim 1,000\right.$ stems $\left.^{-1} \mathrm{~h}^{-1}\right)$.

In many studies investigating branch characteristics in conifers, the number of branches has generally been one of the most difficult attributes to model (e.g. Mäkinen and Colin 1999a, b; Weiskittel et al. 2007), and this was also found to be the case for Sitka spruce. The observation that the number of branches in an annual shoot was positively related to height growth was consistent with the findings of Achim et al. (2006) and Cannell (1974). Likewise, Achim et al. (2006) found that the number of branches in an annual shoot was dependent on its position in the crown even after accounting for annual shoot length; however, a curvilinear relationship was observed in Achim et al. (2006), while a linear relationship was observed in this study. Achim et al. (2006) predicted that, on average, the number of both nodal and internodal branches increased with thinning, while results from this study showed that there was no consistent trend between re-spacing intensity and the number of 
Fig. 4 Predicted vertical branch angle profiles for a live nodal branches (Eq. 1a) and b live internodal branches (Eq. 1b) by re-spacing treatment for the mean branch diameter values in each treatment
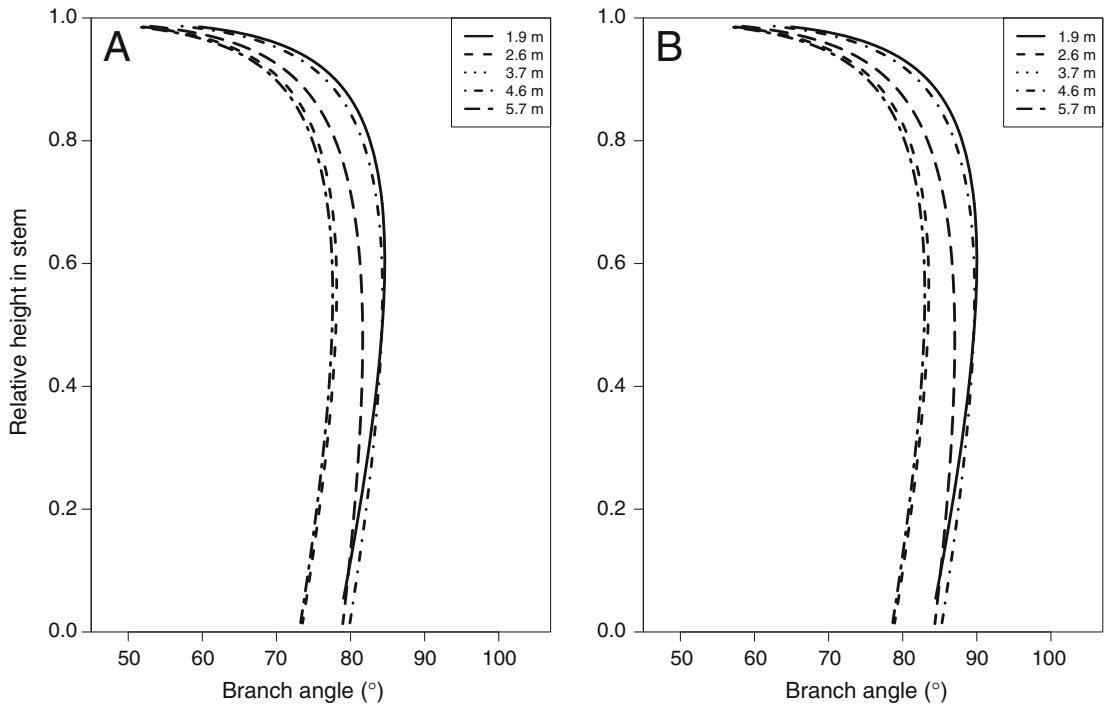

branches. Overall, the branch count model of Achim et al. (2006) performed reasonably well with the current dataset when compared to the models developed in this study, despite being developed using data from a more restricted range of spacings (i.e., 1.7 to $2.4 \mathrm{~m}$ ).

In comparison to other species, Sitka spruce holds many branches (Cannell 1974) and often responds to thinning and pruning treatments with the production of numerous epicormic branches (Deal et al. 2003; Quine 2004). Results from this study indicate that creating a widely spaced stand with an early re-spacing treatment reduced the number of both nodal and internodal branches for a given set of covariates, while highly dense stands will have a greater number of internodal branches. Hein et al. (2008a, b) found that stand density had no effect on the number of branches in widely spaced Douglas-fir, while Mäkinen and Hein (2006) found that Norway spruce [Picea abies (L.) Karst.] trees growing at 1,600 stems $\mathrm{ha}^{-1}$ had slightly fewer branches per annual shoot than trees from stand densities of 350 and 700 stems $^{-1}$. These results indicate that more replication might be necessary in order to better understand the influence of stand density on the number of branches per annual shoot. There could also be a significant interaction between treatment and genetics, as Cannell (1974) found differences in the number of branches between varying seed origins of Sitka spruce.

Branch insertion angle is an important attribute from a wood quality perspective as it determines the area of influence on sawn timber for a particular branch. For example, a lower branch angle for a given branch diameter would result in a larger knot area on sawn timber. The models developed in the current study indicated that insertion angle decreased with increasing branch diameter, which is in agreement with a previous study on radiata pine (Pinus radiata D. Don, Grace et al. 1999). However, the authors of the latter study postulated that if longitudinal rather than cross-sectional data were available, a positive correlation might be expected, a trend which has been observed in both Scots pine (Mäkinen and Colin 1999a, b) and Douglas-fir (Hein et al. 2008a). In the present analysis, branch angle was significantly influenced by stand density. However, the observed differences between re-spacing treatments were small $\left(<5^{\circ}\right)$, which is consistent with several other studies. For example, Weiskittel et al. (2007) found that Douglas-fir branch angle was not influenced by intensive management activities, including thinning, and Hein et al. (2008b) similarly found no influence of stand density in widely spaced Douglas-fir. Despite the high observed variation in branch angle in the present study, only around $33 \%$ of the total variation could be explained by the developed model. Regardless, both the model developed in this present analysis and that of Achim et al. (2006) applied to the current dataset had a relatively similar level of performance.

The distribution of relative branch diameters along the stem gives an indication of the range and variability of branch sizes within an annual shoot. Re-spacing had no influence on the relative diameter distribution within an annual shoot. In this study, the distribution of relative branch sizes was relatively consistent within a Sitka spruce crown, and the decline in relative branch sizes with branch rank was steeper than observed for Douglas-fir (Hein et al. 2008 b), probably due to the greater number of epicormic and internodal branches in Sitka spruce crowns.

\section{Conclusion}

Overall, this study highlighted the important influence that stand density manipulation through early re-spacing can 
have on branch characteristics, particularly size and frequency, which in turn will have an impact on the properties of sawn timber. A large part of this variation in wood properties was accounted for when a densitydependent tree size descriptor (CR or DBH) was included in the analysis, but in the case of maximum branch diameter and the number of branches per annual shoot there was still an additional effect of re-spacing over and above any effects attributable to changes in tree-size. This suggests that wood quality assessments can be improved if the full silvicultural history of the stand is known. It also emphasises the need to pursue the development of wood quality models by including more data from a wide range of silvicultural treatments. The results from this study indicate that early re-spacing of Sitka spruce from $1.9 \mathrm{~m}^{2}$ to no wider than $2.6 \mathrm{~m}^{2}$ will not compromise log or sawn timber quality in terms of the size and frequency of knots.

Acknowledgements We would like to thank Baronscourt Estate and the Northern Ireland Forest Service for allowing access to the trial. Shaun Mochan helped to manage the field project and Elspeth Macdonald, Paul McLean, David Swinson, Floran Pierre, and staff from the Agricultural Food and Bioscience Institute assisted with the field sampling. Drs. Thomas Connolly and Helen McKay provided helpful comments on an earlier version of the manuscript, and we also thank the anonymous reviewers for their valuable comments. The work was funded by the Forestry Commission Corporate and Forestry Services and by a Strategic Research and Development Grant from the Scottish Funding Council.

\section{References}

Achim A, Gardiner BA, Leban J-M, Daquitane R (2006) Predicting the branching properties of Sitka spruce grown in Great Britain. NZ J For Sci 36:246-264

Akaike H (1974) A new look at the statistical model identification. IEEE Trans Autom Control 19:716-723

Barthélémy D, Caraglio Y (2007) Plant architecture: a dynamic, multilevel and comprehensive approach to plant form, structure and ontogeny. Ann Bot-London 99:375-407

Brazier JD (1970) Timber improvement II: the effect of vigour on young growth Sitka spruce. Forestry 43:135-150

Brazier JD (1977) The effect of forest practices on quality of the harvested crop. Forestry 50:49-66

Burnham KP, Anderson DR (2002) Model selection and multimodel inference: a practical information-theoretic approach. Springer, New York

Cannell MGR (1974) Production of branches and foliage by young trees of Pinus contorta and Picea sitchensis: provenance differences and their simulation. J Appl Ecol 11:10911115

CEN (2003) Structural timber-strength classes. EN338:2003, European Committee for Standardization, Brussels, Belgium

Colin F, Houllier F (1991) Branchiness of Norway spruce in north-eastern France: modeling vertical trends in maximum nodal branch size. Ann For Sci 48:679-693

Colin F, Houllier F (1992) Branchiness of Norway spruce in northeastern France: predicting the main crown characteristics from usual tree measurements. Ann Sci Forest 49:511-538
Forestry Commission (2010) Forestry facts and figures 2010: a summary of statistics about woodland and forestry. Forestry Commission, Edinburgh

Deal RL, Barbour RJ, McClellan MH, Parry DL (2003) Development of epicormic sprouts in Sitka spruce following thinning and pruning in south-east Alaska. Forestry 76:401-412

Fonweban JB, Gardiner BA, Macdonald SE, Auty D (2011) Taper functions for Scots pine (Pinus sylvestris L.) and Sitka spruce (Picea sitchensis (Bong.) Carr.) in northern Britain. Forestry 84:49-60

Forest Products Laboratory (2010) Wood handbook, wood as an engineering material. General technical report FPL-GTR-190. U. S. Department of Agriculture, Forest Service, Forest Products Laboratory, Madison, $508 \mathrm{p}$

Garber SM, Maguire DA (2003) Modeling stem taper of three central Oregon species using nonlinear mixed-effects models and autoregressive error structures. Forest Ecol Manag 179:507522

Garber SM, Maguire DA (2005) Vertical trends in maximum branch diameter in two mixed-species spacing trials in the central Oregon Cascades. Can J Forest Res 35:295-307

Gardiner BA, Leban J-M, Auty D, Simpson H (2011) Models for predicting wood density of British-grown Sitka spruce. Forestry $84: 119-132$

Grace JC, Pont D, Goulding CJ (1999) Modelling branch development for forest management. NZ J For Sci 29:391-408

Guilley E, Hervé JC, Nepveu G (2004) The influence of site quality, silviculture and region on wood density mixed model in Quercus petraea Liebl. Forest Ecol Manag 189:111-121

Halsall L, Gilbert J, Matthews, R, Fairgrieve, M (2006) United Kingdom: new forecast of softwood availability. Forestry Commission Edinburgh

Hein S, Weiskittel AR, Kohnle U (2008a) Branch characteristics of widely-spaced Douglas-fir in south-western Germany: comparisons of modelling approaches and geographic regions. Forest Ecol Manag 256:1064-1079

Hein S, Weiskittel AR, Kohnle U (2008b) Effect of wide spacing on tree growth, branch and sapwood properties of young Douglas-fir [Pseudotsuga menziesii (Mirb.) Franco] in southwestern Germany. Eur J Forest Res 127:481-493

Heuret P, Meredieu C, Coudurier T, Courdier F, Barthélémy D (2006) Ontogenetic trends in the morphological features of main stem annual shoots of Pinus pinaster (Pinaceae). Am J Bot 93:15771587

Houllier F, Leban J-M, Colin F (1995) Linking growth modelling to timber quality assessment for Norway spruce. Forest Ecol Manag 74:91-102

Jack WH (1971) The influence of tree spacing on Sitka spruce growth. Irish Forestry 28:13-33

Joyce PM, OCarroll N (2002) Sitka spruce in Ireland. National Council for Forest Research and Development (COFORD), Dublin

Kampstra P (2008) Beanplot: a boxplot alternative for visual comparison of distributions. J Stat Software 28:1-9

Kilpatrick DJ, Sanderson JM, Savill JS (1981) The influence of five early respacing treatments on the growth of Sitka spruce. Forestry 54:17-29

Littel RC, Milliken GA, Stroup WW, Wolfinger RD (2002) SAS system for mixed models. SAS Institute Inc., Cary

Macdonald SE, Hubert J (2002) A review of the effects of silviculture on timber quality of Sitka spruce. Forestry 75:107-138

Macdonald SE, Gardiner BA, Mason WL (2010) The effects of transformation of even-aged stands to continuous cover forestry on conifer $\log$ quality and wood properties in the UK. Forestry 83:1-16

Maguire DA, Kershaw JA, Hann DW (1991) Predicting the effects of silvicultural regime on branch size and crown wood core in Douglas-fir. Forest Sci 37:1409-1428 
Mäkinen H, Colin F (1999a) Predicting the number, death, and selfpruning of branches in Scots pine. Can J Forest Res 29:1225-1236

Mäkinen H, Colin F (1999b) Predicting branch angle and branch diameter of Scots pine from usual tree measurements and stand structural information. Can J Forest Res 28:1686-1696

Mäkinen H, Hein S (2006) Effect of wide spacing on increment and branch properties of young Norway spruce. Eur J Forest Res 125:239-248

Maun KW (1992) Sitka spruce for construction timber: The relationship between wood growth characteristics and machine grade yields of Sitka spruce. Research information note 212. Forestry Commission: Edinburgh, UK.

McCullagh P, Nelder JA (1989) Generalized linear models. Chapman \& Hall, London

Moore JR, Achim A, Lyon A, Mochan S, Gardiner BA (2009) Effects of early re-spacing on the physical and mechanical properties of Sitka spruce structural timber. Forest Ecol Manag 258:1174-1180

Parresol BR (1999) Assessing tree and stand biomass: a review with examples and critical comparisons. Forest Sci 45:573-593

Pinheiro JC, Bates DM (2009) Mixed-effects models in S and SPLUS. Springer, New York

Quine CP (2004) Development of epicormic sprouts on Sitka spruce stems in response to windthrown gap formation. Forestry 77:225-233
R Development Core Team (2011) R: a language and environment for statistical computing. R Foundation for Statistical Computing, Vienna

Schneider R, Zhang SY, Swift DE, Bégin J, Lussier J-M (2008) Predicting selected wood properties of jack pine following commercial thinning. Can J Forest Res 38:2030-2043

Tasissa G, Burkhart HE (1998) An application of mixed effects analysis to modeling thinning effects on stem profile of loblolly pine. Forest Ecol Manag 103:87-101

Wardle PA (1967) Spacing in plantations: a management review. Forestry 40:47-69

Weiskittel AR, Maguire DA, Monserud RA (2007) Modeling crown structural responses to competing vegetation control, thinning, fertilization, and Swiss needle cast in coastal Douglas-fir of the Pacific Northwest, USA. Forest Ecol Manag 245:96-109

Weiskittel AR, Seymour RS, Hofmeyer PV, Kershaw JA (2010) Modelling primary branch frequency and size for five conifer species in Maine, USA. Forest Ecol Manag 259:1912-1921

Worrell R (1987) Geographical variation in Sitka spruce productivity and its dependence on environmental factors. $\mathrm{PhD}$ dissertation. University of Edinburgh, Edinburgh, UK

Zhang S, Chauret G, Ren HQ, Desjardins R (2002) Impact of initial spacing on plantation black spruce lumber grade yield, bending properties, and MSR yield. Wood Fiber Sci 34:460-475 